\title{
Update on the management of overactive bladder: patient considerations and adherence
}

\author{
This article was published in the following Dove Press journal: \\ Open Access Journal of Urology \\ 29 December 2010 \\ Number of times this article has been viewed
}

\author{
Alex Gomelsky' \\ Roger R Dmochowski² \\ 'Department of Urology, Louisiana \\ State University Health Sciences \\ Center - Shreveport, Shreveport, \\ LA, USA; ${ }^{2}$ Department of Urologic \\ Surgery, Vanderbilt University Medical \\ Center, Nashville, TN, USA
}

\begin{abstract}
Overactive bladder (OAB) is a common condition that causes a profound impact on an individual's overall health and quality of life. Muscarinic receptor antagonists are the mainstay of oral pharmacotherapy for OAB. Although all of the medications in this class are significantly more effective than placebo, they are also associated with more adverse events that may limit their overall use. Although newer preparations of these medications have sought to improve tolerability and efficacy through alternative routes of delivery and once-daily dosing, improved adherence to treatment and treatment persistence continue to be an ongoing challenge. An improved understanding of the factors involved in persistence of medical OAB therapy is imperative in efforts to optimize therapeutic benefits in this chronic and potentially morbid condition.
\end{abstract}

Keywords: adherence, overactive bladder, antimuscarinic receptor antagonists

\section{Introduction}

The International Continence Society defines overactive bladder (OAB) as "urgency, with or without urge incontinence, usually with frequency and nocturia". ${ }^{1}$ Extensive research has revealed OAB to be a prevalent, bothersome, and potentially morbid condition. Treatment options for OAB include behavioral therapy and bladder retraining programs, as well as pharmacological and surgical interventions. Owing to the abundance of muscarinic receptors in the bladder, muscarinic receptor antagonists have been the mainstay of the pharmacologic treatment of OAB for many years. ${ }^{2-4}$ Although medications in this class have been effective as a whole in treating the symptoms of $\mathrm{OAB}$, their use is often limited by adverse side effects due to antagonism of muscarinic receptors in other parts of the body. As such, patient compliance and persistence with treatment regimen have become significant concerns during the course of pharmacological therapy for OAB. Our goals are to 1) review the epidemiology and pathophysiology of $\mathrm{OAB}, 2$ ) summarize data regarding available antimuscarinic agents, and 3) comment on factors influencing patient compliance and persistence with treatment.

\section{Epidemiology of OAB}

Department of Urologic Surgery, Vanderbilt University Medical Center, A-I302, Medical Center North, Nashville, TN 37232, USA

Tel +l 6153435602

Fax + I 6153228990

Email roger.dmochowski@vanderbilt.edu
The substantial prevalence of OAB has been well documented in several populationbased, cross-sectional surveys. Out of more than 19,000 participants in five countries enrolled in the EPIC study, nearly $65 \%$ reported at least one lower urinary tract symptom (LUTS). ${ }^{5}$ The prevalence of storage symptoms (men, 51.3\%; women, $59.2 \%$ ) was greater than that for voiding symptoms (men, 25.7\%; women, 19.5\%) and postmicturition 
symptoms (men, 16.9\%; women, 14.2\%) combined. The overall prevalence of $\mathrm{OAB}$ was $11.8 \%$, and rates were similar in men and women, increasing with age for both sexes. The National Overactive Bladder Evaluation (NOBLE) study has estimated an even greater overall prevalence of OAB of $16.9 \%$ in women and $16.2 \%$ in men. ${ }^{6}$ In the United States alone, these numbers correspond to $\sim 33$ million adults who have OAB: 12 million with urgency urinary incontinence (UUI) and 21 million without incontinence. The authors found that in relation to chronic health disorders such as diabetes, heart disease, and asthma, OAB was only second to arthritic symptoms in terms of overall prevalence. ${ }^{6}$

The impact of OAB on quality of life (QoL) is likewise significant in both women and men. In a US online survey of nearly 900 women currently being treated, lapsed in treatment, and never treated for OAB, over one-third of respondents indicated that $\mathrm{OAB}$ symptoms interfered with their daily activities and their ability to participate in physical activities. ${ }^{7}$ Additionally, 23\% were not able to go on short outings, and $12 \%$ stayed at home more often. In subanalyses of the EPIC study, patients with LUTS reported significantly greater symptom bother, worse health-related QoL (HRQol), higher rates of depression, decreased enjoyment of sexual activity, and decreased work productivity than other subgroups. ${ }^{8,9}$ Likewise, men in the NOBLE study with OAB (with and without UUI) had clinically and significantly lower SF-36 QoL scores, higher CES-D depression scores, and poorer quality of sleep than matched controls. ${ }^{6}$ Furthermore, the prevalence of falls, fractures, and other comorbidities was significantly higher for patients with $\mathrm{OAB}$ than for those without OAB. ${ }^{10,11}$

The economic impact of OAB diagnosis and treatment is also impressive. A subanalysis of the NOBLE study estimated the total cost of urinary incontinence and OAB to be $\$ 19.5$ and $\$ 12.6$ billion in year 2000, respectively. ${ }^{12}$ With OAB, $\$ 9.1$ and $\$ 3.5$ billion was incurred by community and institutional residents, respectively. These numbers are likely an underestimate when one considers that the population is aging rapidly. A report by the US Census Bureau noted that although the total US population has increased 2 -fold in the past century, the population of Americans of ages 60 years and older has increased 10-fold to 35 million in the year 2000. ${ }^{13}$ Additionally, the number of Americans older than 80 years of age is expected to increase by almost $70 \%$ from 2000 to 2030 . Unfortunately, the actual number of patients receiving treatment may be quite low despite the obvious effects of OAB on QoL and costs to society. ${ }^{7}$ Out of over 160,000 survey respondents with probable OAB, only
$45.7 \%$ had discussed the symptoms with a medical provider, $22.5 \%$ had previously used prescription medications for OAB, $13.5 \%$ had used OAB medications in the last 12 months, and $8.1 \%$ were currently undergoing treatment. ${ }^{14}$

\section{Pathophysiology of urinary storage and OAB}

Normal physiological adaptations during urinary storage and emptying are facilitated by an interaction between the bladder body and outlet, which are innervated by peripheral nerves involving the sympathetic, parasympathetic, and somatic nervous systems. ${ }^{15}$ Efferent axons in the sympathetic nerves inhibit bladder contraction and stimulate contractibility of the urethra to promote urinary storage, while parasympathetic nerves stimulate bladder contraction and relax the bladder outlet to promote urinary emptying. The somatic nervous system controls the external urethral sphincter and pelvic floor musculature.

Urinary storage is achieved primarily by spinal reflex pathways under the control of the periaqueductal gray and the pontine micturition center in the brainstem. Increased wall tension during filling activates bladder afferent nerves, which, in turn, reflexively activate sympathetic outflow to the lower urinary tract from the lumbosacral spinal cord. ${ }^{16,17}$ As a result, there is internal sphincter contraction and ganglionic inhibition via the hypogastric nerve, as well as contraction of the external sphincter and pelvic floor striated musculature via the pudendal nerve. The sacral parasympathetic outflow is typically inactive during the storage phase. The outcome of these adaptations is detrusor inhibition and outlet excitation, resulting in continent, low-pressure storage of urine.

Symptoms of OAB such as urgency and UUI are often associated with detrusor overactivity (DO), an urodynamic observation characterized by involuntary detrusor contractions during bladder filling. ${ }^{1,18}$ The development of DO is complex and may be influenced by factors such as hormonal changes, bladder outlet obstruction (BOO), aging, ischemia, and concomitant neurologic conditions. ${ }^{19}$ Additionally, mechanisms contributing to OAB symptoms may be sensory or motor, and may be neurogenic, myogenic, mixed, or idiopathic in origin. ${ }^{18,20}$ Traditionally, DO was thought to result from a decreased capacity to handle increased afferent information, or from a decrease in tonic inhibition of afferent impulses. ${ }^{20}$ Bladder contractions often seen during normal bladder filling may be suppressed with a voluntary increase in suprapontine inhibition; however, suprapontine inhibition may be impaired in conditions such as stroke. As a result, involuntary detrusor contractions may be generated from 
low-intensity afferent input and at lower bladder volumes. Conditions such as BOO, normal aging, and neurogenic insult may also lead to morphologic changes in the detrusor, resulting in progressive denervation and hypertrophy of the bladder wall ('myogenic theory'). ${ }^{19,21-23}$

Recently, Andersson proposed an important cascade of further peripheral events that may result in $\mathrm{DO}$ and $\mathrm{OAB} .{ }^{20} \mathrm{An}$ enhanced reaction to heightened wall tension and stretching of the detrusor smooth muscle may lead to increased afferent signaling during bladder filling. Additionally, increased afferent activity may result from increased urothelial signaling to suburothelial nerves, as may be seen in BOO and normal aging. It has been proposed that there is an increased amount of acetylcholine (Ach) released from the urothelium during bladder filling, above and beyond the typical basal Ach release. The increase in Ach release from neuronal and nonneuronal (urothelial) sources increases the sensitivity of the detrusor to neurotransmitters. The resultant micromotion of the detrusor increases the afferent signaling in the suburothelium and detrusor, leading to the sensation of urgency. It is this latter mechanism that is increasingly thought to be the target for the actions of antimuscarinic medications.

\section{Muscarinic receptors and binding characteristics}

Five muscarinic receptor subtypes have been defined pharmacologically (M1-M5), and consistent expression of M1-M3 and M5 muscarinic receptors has been found in the urothelium and lamina propria using molecular techniques. ${ }^{24,25}$ In humans, M2 receptors appear to outnumber M3 receptors (which mediate bladder contraction) by $\sim 4: 1 .^{26,27}$ Muscarinic receptors have been found in three locations within the urinary bladder. Activation of these receptors in the detrusor smooth muscle causes contraction, while activation of urothelial receptors causes the release of a factor that inhibits detrusor contraction. Finally, activation of receptors on parasympathetic and sympathetic nerve endings influences transmitter release. ${ }^{26}$ Traditionally, it was thought that muscarinic receptor antagonists mediated their effects by blocking receptors on the detrusor muscle, thus inhibiting bladder contraction due to Ach release from parasympathetic nerves. However, at therapeutic doses, muscarinic antagonists do not appear to inhibit bladder contractility. ${ }^{2,28}$ Furthermore, the density of urothelial muscarinic receptors appears to be twice that found in the detrusor smooth muscle. ${ }^{29}$ Thus, it is now considered that muscarinic antagonists increase bladder capacity and decrease urgency mainly during bladder filling by their action at the urothelial muscarinic receptors.

\section{Pharmacologic treatment with muscarinic receptor antagonists}

Antimuscarinic medications are the mainstay of pharmacologic therapy for symptoms associated with OAB. The available drugs in this class (oxybutynin, tolterodine, solifenacin, darifenacin, trospium, and fesoterodine) all block the muscarinic receptor but differ in several ways. Although most of the agents are tertiary amines, trospium is a quaternary amine and does not cross the blood-brain barrier. Oxybutynin is available in a transdermal patch and transdermal gel applications. This application bypasses drug metabolism in the liver and may be associated with a lower incidence of adverse events, such as dry mouth and constipation. Oxybutynin, tolterodine, and trospium are available in immediate-release (IR) preparations, which are administered 2-3 times/day. All of the medications are available in extended-release (ER), once-daily preparations. Specific details regarding the pharmacological properties of available muscarinic receptor antagonists are given in Table 1 .

\section{Oxybutynin}

Chemically, oxybutynin is D, L (racemic) 4-diethylamino2-butynyl phenylcyclohexylglycolate and is administered as a racemic (50:50) mixture of $\mathrm{R}$ - and $\mathrm{S}$-isomers. IR oxybutynin is metabolized within the small intestine and then primarily through hepatic first-pass metabolism, limiting its bioavailability to $6 \% .{ }^{30}$ A percentage of the parent drug is converted to the active metabolite $N$-desethyloxybutynin ( $N$-DEO) before reaching the bladder or the salivary glands, bowel, eye, and brain, the other organs primarily responsible for side effects. ${ }^{31} N$-DEO has pharmacological activity on the human detrusor muscle that is similar to that of oxybutynin during in vitro studies. The $N$-DEO to oxybutynin ratio in oxybutynin IR is $\sim 5.5: 1$.

A once-daily, ER formulation of oxybutynin was approved by the US Food and Drug Administration (FDA) in 1999. This formulation uses osmotic pressure to deliver oxybutynin at a controlled rate over $\sim 24 \mathrm{~h}^{32}$ The osmotic release oral system (OROS) comprises an osmotically active bilayer core surrounded by a semipermeable membrane. The bilayer core comprises a drug layer containing the drug and excipients, and a push layer containing osmotically active components. There is a precision-laser-drilled orifice in the semipermeable membrane on the drug layer side of the tablet. In an aqueous environment, such as the gastrointestinal tract, water permeates through the membrane into the tablet core, causing the drug to go into suspension and the push layer to expand. This expansion pushes the suspended drug out 


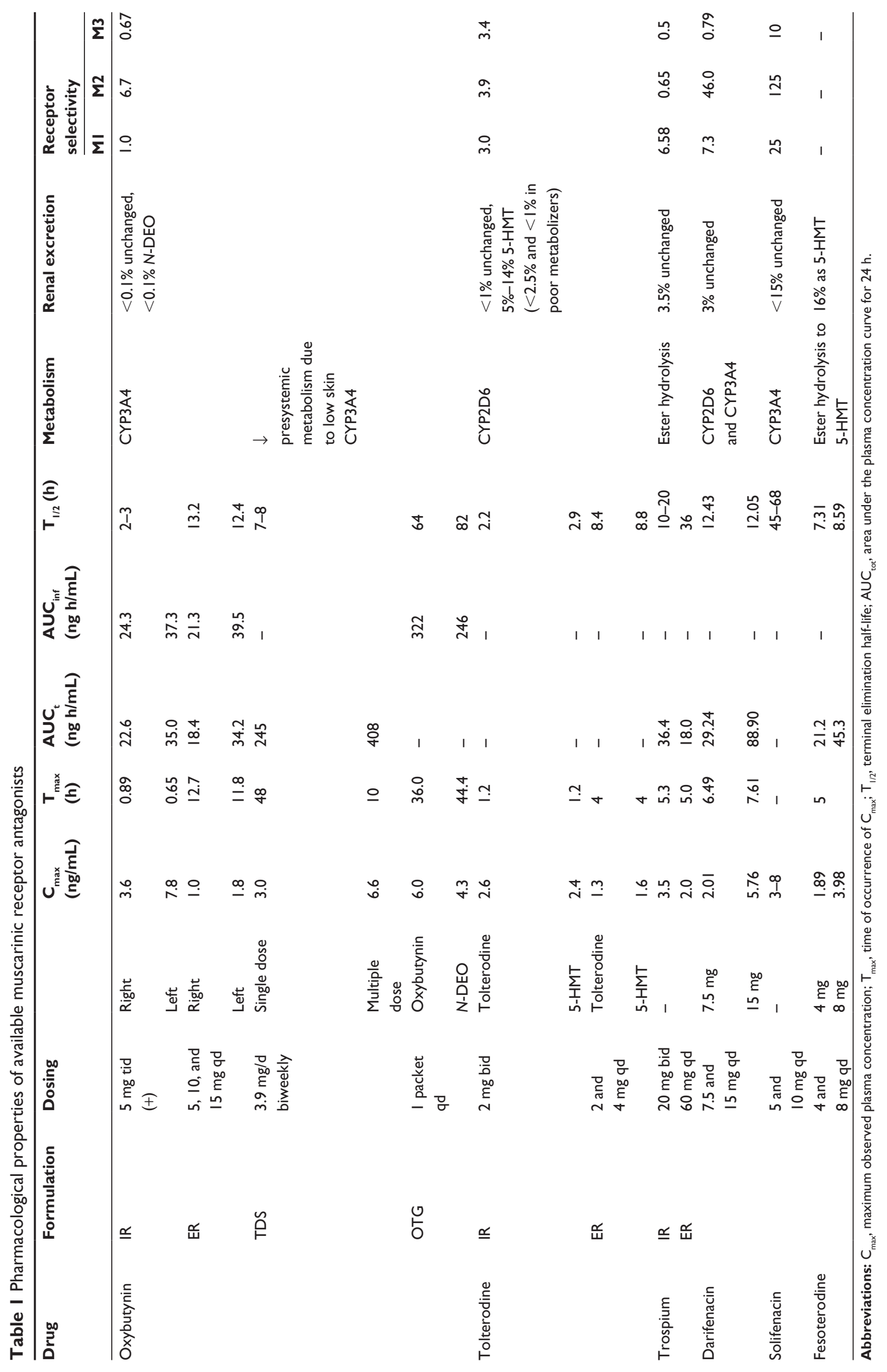


through the orifice. The semipermeable membrane controls the rate at which water permeates into the tablet core, which, in turn, controls the rate of drug delivery. Plasma levels of oxybutynin increase over a 4- to 6-h period and achieve steady state concentration after 3 days of ingestion. ${ }^{32,33}$ Compared with oxybutynin IR, the relative bioavailabilities of R- and S-oxybutynin in the ER formulation are 156\% and $187 \%$, respectively. ${ }^{32}$ The rate and extent of absorption and metabolism of oxybutynin are similar under fed and fasting conditions. The $N$-DEO to oxybutynin ratio in oxybutynin ER is $\sim 4.3: 1$.

Transdermal formulations of contraceptives, hormones, and analgesics have been attractive alternatives to their oral counterparts for their ability to bypass the organs involved in first-pass metabolism and to yield more stable plasma drug levels in the delivery. ${ }^{34}$ Likewise, oxybutynin has recently become available in two transdermal preparations, a patch and gel. As with the aforementioned drugs, transdermal metabolism of oxybutynin is minimal due to the low cytochrome P450 content of the epidermis. ${ }^{35,36}$ The oxybutynin transdermal delivery system (oxy-TDS patch) contains $36 \mathrm{mg}$ of oxybutynin, and the osmotic gradient and enhancer provide an average in vivo delivery rate of $3.9 \mathrm{mg}$ /day through skin of average permeability. ${ }^{37}$ The matrix system in oxy-TDS is composed of a backing film, an adhesive/drug layer, and an overlapping release liner. ${ }^{37}$ The backing film is a thin flexible polyester/ethylene-vinyl acetate film that provides the matrix system with occlusivity and physical integrity and protects the adhesive/drug layer. The adhesive/drug layer is a cast film of acrylic adhesive containing oxybutynin and triacetin. Upon application of the patch, skin hydration occurs, followed by diffusion of both the oxybutynin and the triacetin across the stratum corneum. The physiochemical interaction of the permeation enhancer with the lipids in the skin controls the rate of oxybutynin diffusion. Steady state is reached during the first patch application, and steady state plasma concentrations are maintained for $\sim 96 \mathrm{~h} .{ }^{38}$ The $N$-DEO to oxybutynin ratio in oxy-TDS is $\sim 1.3: 1$.

Oxybutynin chloride topical gel (OTG) is another topical preparation that was developed to achieve favorable $N$-DEO to oxybutynin ratios, decrease antimuscarinic side effects, and minimize application-site reactions..$^{39,40}$ OTG is packaged in single, daily-dose sachets that contain $1 \mathrm{~g}(1.14 \mathrm{~mL})$ of OTG, which is applied once daily to the abdomen, upper arms, shoulders, or thighs. OTG contains $10 \%$ oxybutynin by weight (100 mg/dose), as well as ethanol to function as a skin permeation enhancer and glycerin emollient to soften skin and minimize application site dryness. ${ }^{39,40}$ Single-dose and steady state pharmacokinetics of OTG in healthy subjects revealed an $\sim 0.8: 1 \mathrm{~N}$-DEO to oxybutynin plasma concentration ratio, and direct comparison of the steady state pharmacokinetic profiles of OTG and TDS showed that the two profiles were similar. ${ }^{40}$

\section{Tolterodine}

Another competitive muscarinic receptor antagonist, tolterodine, is metabolized in the liver by cytochrome $\mathrm{P} 450$ 2D6 to its major pharmacologically active metabolite 5-hydroxymethyl tolterodine (5-HMT). Tolterodine IR has stronger selectivity for the bladder than for the salivary gland and is administered at $2 \mathrm{mg}$ twice daily. Less than $10 \%$ of the population lacks CYP2D6, the enzyme responsible for the formation of 5-HMT. The identified pathway of metabolism for these individuals ('poor metabolizers') is dealkylation via CYP3A4 to $N$-dealkylated tolterodine. The remainder of the population is referred to as 'extensive metabolizers'. Pharmacokinetic studies revealed that tolterodine is metabolized at a slower rate in poor metabolizers than in extensive metabolizers, resulting in significantly higher serum concentrations of tolterodine and in negligible concentrations of 5-HMT.

Tolterodine ER employs a unique drug delivery system containing soluble microspheres. ${ }^{41}$ As the outer layer of the microsphere dissolves, the drug is slowly released, providing constant delivery over $24 \mathrm{~h}$ over the entire physiologic $\mathrm{pH}$ range of the gastrointestinal tract. In a randomized, openlabel, crossover study, the maximum observed serum concentration $\left(\mathrm{C}_{\text {max }}\right)$ of tolterodine ER was $\sim 75 \%$ that of tolterodine IR. ${ }^{42}$ The minimum observed concentration $\left(\mathrm{C}_{\min }\right)$ was about $150 \%$ higher, while the area under the curve (AUC) of tolterodine ER was equivalent to that of tolterodine IR. Thus, the administration of tolterodine ER was associated with fewer peaks and troughs seen with the IR formulation.

\section{Trospium chloride}

Trospium IR (20 mg twice daily) was originally approved by the FDA in 2004. As mentioned previously, trospium is the only available muscarinic receptor antagonist that is a hydrophilic, quaternary ammonium compound. This is in contrast to the other antimuscarinic agents that are uncharged and lipophilic in nature. Owing to its positive charge, trospium does not cross the blood-brain barrier, which theoretically reduces the potential of central nervous system adverse events. Additionally, trospium is metabolized by ester hydrolysis, which may limit potential metabolic drug-drug interactions that may be observed after administration of antimuscarinics metabolized by the cytochrome p450 system. 
Furthermore, as the parent compound may be largely eliminated unchanged in the urine, this medication may provide some local effects on the urothelium. ${ }^{43}$ In 2007, trospium chloride ER (60 mg once daily) gained FDA approval. The new formulation releases trospium using a capsule that contains pellets that dissolve in a time- and $\mathrm{pH}$-dependent manner, lowering the $\mathrm{C}_{\max }$ and delivering the drug to maintain therapeutic levels over a $24-\mathrm{h}$ period. ${ }^{44} \mathrm{C}_{\max }$ may be lower in the ER formulation and may result in an improvement in the adverse event profile while maintaining the efficacy of the twice-daily IR preparation.

\section{Darifenacin, solifenacin, and fesoterodine}

Darifenacin hydrobromide has a higher affinity for the M3 receptor and has the theoretical advantage of decreased central nervous system and cardiac effects. ${ }^{45,46}$ It is available in two doses, 7.5 and $15 \mathrm{mg}$. Owing to its extensive metabolism by liver CYP2D6 and CYP3A4, the renal excretion of darifenacin is negligible. ${ }^{47}$ Solifenacin succinate is a competitive M3 antagonist available in 5 and $10 \mathrm{mg}$ doses. Unlike other muscarinic receptor antagonists, a significant percentage of the oral dose of solifenacin is eliminated renally as the parent compound. Solifenacin has the longest elimination half-life of all antimuscarinics, and steady state serum concentration is achieved after 10 days of consecutive dosing. ${ }^{48,49}$

Fesoterodine is a nonspecific, competitive muscarinic receptor antagonist that, by itself, is not a potent antimuscarinic agent. A matrix platform is used for the ER delivery of fesoterodine. ${ }^{50}$ Upon ingestion, the outer polymer layer swells to form a gel layer surrounding the tablet, which controls the release of fesoterodine. After oral administration, fesoterodine is rapidly and extensively hydrolyzed by nonspecific esterases to its active metabolite, 5 -HMT. ${ }^{51}$ 5-HMT is a nonselective blocker of muscarinic receptors and is responsible for the antimuscarinic activity of fesoterodine. Hydrolysis of fesoterodine is so rapid and extensive that no parent compound is detectable in plasma after oral administration. ${ }^{52}$ Fesoterodine is available in 4- and 8-mg daily doses. Although they share 5-HMT as a common active metabolite, there are some important differences between tolterodine and fesoterodine. Owing to its breakdown by nonspecific esterases, administration of fesoterodine may not be affected by genotypic variations in CYP enzymes. Likewise, drugdrug interactions may be less common. After oral administration of fesoterodine, $\sim 70 \%$ of the administered dose was recovered in the urine as the active metabolite (16\%), carboxy metabolite (34\%), carboxy- $N$-desisopropyl metabolite (18\%), or $N$-desisopropyl metabolite (1\%). A smaller amount (7\%) is recovered in the feces.

\section{Outcomes after treatment with muscarinic receptor antagonists}

Reports of the efficacy of antimuscarinic medications are common in the literature. Several Cochrane systematic reviews have been compiled to evaluate the impact of OAB treatment with muscarinic receptor antagonists. In a review of 61 trials with over 11,000 patients comparing placebo and treatment with several muscarinic receptor antagonists, the authors found that cure or improvement, difference in leakage episodes per $24 \mathrm{~h}$, and difference in number of voids in $24 \mathrm{~h}$ were statistically significant favoring medication. ${ }^{53}$ The majority of the trials were double-blinded. Another Cochrane review provided evidence that treatment with antimuscarinic medications provided more symptomatic improvement than bladder training. ${ }^{54}$ The combination of antimuscarinics and bladder training was also associated with more improvement than bladder training alone. Similarly, the limited data favored a combination of antimuscarinics with bladder training compared with antimuscarinics, although the difference was not statistically significant. In a separate review of 49 trials encompassing more than 11,000 patients, the authors found no statistically significant differences in patient-perceived improvement, leakage episodes, or voids in $24 \mathrm{~h}$ in patients on oxybutynin versus tolterodine. ${ }^{55}$

A recent systematic review performed by Chapple et al also evaluated the effect of muscarinic receptor antagonists on OAB. ${ }^{56}$ The review encompassed 211 publications describing 83 trials. As in the Cochrane analysis, active treatment with antimuscarinics was found to be statistically more effective than placebo in terms of the mean change in the number of incontinence episodes per day. Pooled differences in mean changes ranged from 0.4 to 1.1 incontinence episodes/day. Active treatments were also more effective than placebo in the mean change in the number of micturition episodes per day. Statistically significant results were obtained for both of the aforementioned variables for interventions involving each licensed drug, with the exception of trospium, which was not reported. Pooled differences in mean changes of micturitions per day ranged from 0.5 to 1.3 episodes/day. Fesoterodine, solifenacin, and tolterodine were statistically significantly more effective than placebo in terms of mean change in the number of urgency episodes per day. The outcomes for oxybutynin and trospium chloride were not suitable for meta-analysis. Pooled differences in mean changes varied between 0.64 and 1.56 episodes/day. There was some 
evidence favoring solifenacin 5 and $10 \mathrm{mg} /$ day over tolterodine IR $4 \mathrm{mg} /$ day. Otherwise, there were no statistically significant differences among active treatments.

Active treatments were all statistically significantly more effective than placebo in the mean change in the volume voided per micturition. ${ }^{56}$ Differences in pooled mean changes were $13-40 \mathrm{~mL}$. Several statistically significant relationships were found: solifenacin $10 \mathrm{mg} /$ day was favored over tolterodine IR $4 \mathrm{mg}$ /day; solifenacin $10 \mathrm{mg}$ /day was favored over solifenacin $5 \mathrm{mg}$ /day; fesoterodine $8 \mathrm{mg} /$ day was favored over tolterodine ER $4 \mathrm{mg} /$ day; and oxybutynin IR $15 \mathrm{mg} /$ day was favored over tolterodine IR $4 \mathrm{mg}$ /day. Finally, 37 of 83 trials (44\%) reported HRQoL. ${ }^{56}$ Statistically significant differences in HRQoL were reported for darifenacin, fesoterodine, oxybutynin TDS, solifenacin, tolterodine IR and ER, and trospium.

The efficacy of oxybutynin OTG has been evaluated in a multisite, randomized, placebo-controlled trial. ${ }^{57}$ Patients treated experienced a significant reduction in daily UUI episodes, daily frequency of urination, and significant increases in voided volume per micturition when compared with placebo.

\section{Safety and adverse events with muscarinic receptor antagonists}

Although effects on $\mathrm{M} 3$ receptors, the primary mediators of detrusor contractility, are universal to all available antimuscarinics, their effects at other receptors may vary. ${ }^{58,59}$ The M1 receptor is found in the cerebral cortex, hippocampus, eyes, and salivary glands, with blockade impacting memory, cognitive function, saliva, and tear production. M2 receptors are located in cardiac muscle, eyes, bronchial smooth muscle, hippocampus, and hind brain. Blockade of these receptors may cause tachycardia and may impact tear secretion and bronchodilation. In addition to affecting bladder motility, blockade of the $\mathrm{M} 3$ receptor may affect visual accommodation, as well as saliva and tear secretion. Although all of the antimuscarinic medications differ in their selectivity for the M3 receptor, it is not currently clear if increased selectivity results in greater clinical efficacy. ${ }^{60}$

In their systematic review, Chapple et al evaluated the safety profiles of antimuscarinic medications. ${ }^{56}$ Every treatment in the review except tolterodine IR $2 \mathrm{mg} /$ day and oxybutynin TDS was associated with a statistically greater risk of adverse events than placebo. No treatment was shown to be significantly associated with serious adverse events. There were favorable results for tolterodine formulations relative to other active treatments. The risk of adverse events was significantly lower with tolterodine IR $2 \mathrm{mg} /$ day than with oxybutynin ER $5 \mathrm{mg} /$ day and lower with tolterodine IR $4 \mathrm{mg}$ /day than oxybutynin IR 7.5-15 mg/day. One trial suggested that fesoterodine $8 \mathrm{mg}$ /day was associated with a higher risk of adverse events than fesoterodine $4 \mathrm{mg}$ /day and tolterodine ER $4 \mathrm{mg} /$ day. The remaining statistically significant result favored trospium $40 \mathrm{mg}$ /day over oxybutynin IR $7.5-10 \mathrm{mg}$ /day. No other treatment in the review was associated with a significantly greater risk of serious adverse events than placebo or another active treatment.

In the aforementioned review, dry mouth was the most frequently reported adverse event, reported by $29.6 \%$ and $7.9 \%$ of active treatment and placebo arm patients, respectively. ${ }^{56}$ Dry mouth of any severity (mild, moderate, or severe) was found to be significantly more common in all interventions when compared with placebo. There was a dose-dependent relationship, as the risk ratio generally increased with drug dose for darifenacin, fesoterodine, solifenacin, and tolterodine. A meta-analysis encompassing over 100 randomized controlled trials involving nearly 20,000 patients demonstrated that patients treated with antimuscarinic OAB medications are significantly more likely to experience constipation. ${ }^{61}$ The odds ratios (OR) for constipation compared with placebo were as follows: overall (OR 2.18), tolterodine (OR 1.36), darifenacin (OR 1.93), fesoterodine (OR 2.07), oxybutynin (OR 2.34), trospium (OR 2.93), and solifenacin (3.02).

As oxybutynin is the only antimuscarinic agent available in a transdermal application, pruritus was another common adverse event (15.4\% on treatment versus $5.2 \%$ on placebo). ${ }^{62,63}$ Approximately $86 \%$ of those reactions were classified as mild to moderate. Additionally, blurred vision, constipation, erythema, fatigue, increased sweating, and urinary retention were reported at significantly higher levels in active treatments than in placebo. ${ }^{56}$ Side effect profiles are especially important in considering the aging population, as antimuscarinic side effects may be additive with those of other medications or may counteract other medications. When oxybutynin IR was administered to patients of 65-76 years of age, a significant impairment was noted in memory and speed on cognitive testing. ${ }^{64}$ On the other hand, 150 subjects of ages 60 years and older taking darifenacin showed no significant changes over placebo in 13 of 15 endpoints assessing memory and cognitive function. ${ }^{65}$

\section{Tolerability, drug adherence, and patient considerations}

The presence or absence of adverse events is known to be a major contributing factor to the tolerability outcomes of 
various antimuscarinic medications. ${ }^{56}$ In the systematic review, withdrawals due to any cause were frequently reported. Oxybutynin IR in doses ranging from 7.5 to $15 \mathrm{mg}$ / day was associated with significantly higher risk of withdrawal from trial due to any cause than placebo. Otherwise, no statistically significant differences in proportions of patients who withdrew from trials for any causes were found between placebo and any other active treatment. Statistically significant differences in withdrawal from trial due to any cause among active treatments were oxybutynin IR 7.5-10 mg/day over oxybutynin ER $5 \mathrm{mg}$ /day, oxybutynin IR 7.5-10 mg/day over tolterodine ER $4 \mathrm{mg} /$ day and tolterodine IR $4 \mathrm{mg} /$ day, and oxybutynin IR $15 \mathrm{mg}$ /day over tolterodine IR $4 \mathrm{mg}$ /day and oxybutynin ER $15 \mathrm{mg} /$ day. Tolterodine ER $4 \mathrm{mg} /$ day was the only formulation found to be associated with a significantly lower risk than placebo of withdrawal due to an adverse event. Oxybutynin IR 7.5-15 mg/day and solifenacin $10 \mathrm{mg} /$ day were found to be associated with a significantly higher risk of withdrawal due to adverse events than placebo. Additionally, tolterodine ER $4 \mathrm{mg} /$ day was associated with a lower risk of this outcome than oxybutynin TDS and oxybutynin IR $15 \mathrm{mg} /$ day. Tolterodine IR $4 \mathrm{mg} /$ day was associated with a lower risk than oxybutynin IR $15 \mathrm{mg} /$ day, and oxybutynin ER $5 \mathrm{mg} /$ day was associated with a lower risk than oxybutynin ER $15 \mathrm{mg} /$ day. There were no other statistically significant differences among active treatments.

As persistence with a medication has been shown to be a critical predictor of outcomes in chronic conditions such as $\mathrm{OAB}$, it would be safe to conclude that discontinuation or nonpersistence of an OAB medication is multifactorial. ${ }^{66}$ Some authors have postulated that the setting, characteristics of the study population, and cost all play a significant role. ${ }^{67}$ Others have suggested that low levels of formal education and cultural factors can also lead to poor compliance. ${ }^{6,69} \mathrm{Of}$ interest, however, is that $\mathrm{OAB}$ medication persistence rates have been low regardless of setting or population. In a study of more than 33,000 commercially insured patients over a 3-year period, the levels of persistence and compliance with tolterodine and oxybutynin were evaluated. ${ }^{70}$ Persistence was calculated based on the time (in days) from therapy initiation until the first discontinuation, and was also calculated on a monthly basis over a 12-month follow-up period from therapy initiation. First discontinuation was defined as a gap in therapy exceeding 2 times the therapy days supplied on the previous prescription. Compliance was expressed as a ratio of the number of therapy days supplied divided by the persistence measure previously described. In general, patients receiving medication for $\mathrm{OAB}$ were relatively compliant but not persistent. The average compliance rate was $74 \%$ for the entire group, with the highest compliance seen in the patients on tolterodine ER (77.4\%). Oxybutynin ER and IR patients had lower compliance rates of $74.3 \%$ and $61 \%$, respectively. Overall persistence was low, with $\sim 75 \%$ of treated patients discontinuing therapy within 6 months. On an average, patients were persistent on therapy for 113 days. The mean persistence was highest amongst patients receiving tolterodine ER when compared with those receiving oxybutynin ER and IR (139 versus 115 and 60 days, respectively). There was also a slight cost benefit to using tolterodine ER versus oxybutynin ER and IR.

Persistence has also been evaluated in Medicaid beneficiaries. Yu et al investigated 1-year persistence patterns for OAB medications in a large study of California Medicaid beneficiaries. ${ }^{71}$ Persistence patterns were measured as time to discontinuation, while adherence was measured as the medication possession ratio (MPR), which compares the cumulative days of drug supply with the elapsed time since the date of the first prescription of the drug. Out of nearly 2500 eligible patients, $\sim 37 \%$ had only one OAB prescription. The mean MPR was 0.34 and the median was 0.3 , indicating that, on average, only about one-third of the time since medication initiation was covered by the therapy. Only 122 patients exhibited $>80 \%$ adherence during the 6-month follow-up period. Significant predictors of higher persistence included white ethnicity; previous hospitalization length, starting with tolterodine or oxybutynin ER; and previous use of topical drugs or antipsychotics. Polypharmacy and previous diagnosis of depression or UTI significantly increased the odds of early discontinuation. The study also suggested that there may be adverse effects to therapy discontinuation, as the risk of UTI was $37 \%$ higher in those patients who discontinued drug therapy.

An additional study evaluated the persistence with OAB therapy in a Medicaid population over a 3 -year period. ${ }^{72}$ Out of 1637 patients, 182 were started on tolterodine ER, 215 on oxybutynin ER, and 1240 on oxybutynin IR. Only $32 \%$ of those taking oxybutynin IR and $44 \%$ of those taking either ER agent remained adherent past 30 days. This difference may have been associated with the high proportion of younger patients taking prescribed oxybutynin IR. Of those remaining after 30 days, the risk of nonadherence was higher for oxybutynin ER than for tolterodine ER. Thus, persistence rates appeared better for patients taking drugs with oncedaily dosing.

Another study examined adherence to OAB medications if they are provided for free. ${ }^{73} \mathrm{OAB}$ medications were 
prescribed to nearly 7900 military adults, with $60 \%$ receiving tolterodine ER and $25.5 \%$ receiving oxybutynin IR. The medication nonpersistence rate, defined as the proportion of patients who never refilled a prescription for antimuscarinics during the study period, was $35.1 \%$. Of the $\sim 5100$ patients who refilled a prescription, $25.6 \%$ changed the medication or dose at least once. The MPR was 0.82 in all cases (higher than previously reported). Of patients who obtained at least one refill, women remained on medication longer than men.

Finally, results of pharmacy claims database reveal similar results. ${ }^{74}$ Out of over 1100 patients who had at least one pharmacy claim for an OAB study drug, 44.5\% did not have a refill after the initial (index) pharmacy claim $(39.4 \%$ for oxybutynin ER, $42.7 \%$ for tolterodine ER, $46.1 \%$ for tolterodine IR, and 59.3\% for oxybutynin IR; $P=0.004$ ). Only $13.2 \%$ persisted with treatment for at least 1 year. The nonpersistence rate, measured as median days to discontinuation, was 31 overall, 33 for tolterodine ER, 34 for oxybutynin ER, 32 for tolterodine IR, and 0 for oxybutynin IR. Of patients who refilled their initial prescription at least once, $24 \%$ made a medication switch. Adherence rates, as measured by percentage of patients with MPR $\geq 80 \%$, were $30.3 \%$ overall and higher for the ER formulations.

\section{Conclusion}

$\mathrm{OAB}$ is already considered to be a prevalent and morbid chronic condition, one that promises to become only more prevalent in a rapidly aging population. Muscarinic receptor antagonists are widely considered to be the initial pharmaceutical intervention in the treatment of $\mathrm{OAB}$, and are now thought to exert their effects during the urinary storage phase. In addition to several immediate-release and ER oral medications, newly introduced transdermal preparations have added to the armamentarium. The medications vary in their lipophilicity, their specificity for the M3 receptor, and their metabolism by the human body. Several meta-analyses and systematic reviews have concluded that all muscarinic receptor antagonists are statistically better than placebo in improving several OAB indices. In general, dose escalation appears to improve efficacy, while reports of superiority of one antimuscarinic versus another active treatment are infrequent. Common adverse events, such as dry mouth and constipation, were typically dose dependent, and adverse events as a whole were rarely severe.

Although low persistence with OAB medications, regardless of population and drug cost, is echoed in most studies, the data trend toward showing better persistence with tolterodine (versus oxybutynin) and ER preparations (versus multiple-daily dosing). However, there are currently gaps in our understanding. First, as these studies are retrospective, patient-reported side effect data were often not available. Second, comparisons with newer oral antimuscarinic agents have not yet been performed. Finally, studies of transdermal preparations have shown that these drugs are associated with favorable adverse event profiles due to bypassing first-pass metabolism. However, persistence analyses are likewise lacking. Perhaps a behavior-modifying education program would be of value to patients with OAB, in light of this condition's chronic nature. ${ }^{72}$

\section{Disclosure}

The authors report no conflicts of interest in this work.

\section{References}

1. Abrams P, Cardozo L, Fall M, et al. The standardisation of terminology in lower urinary tract function: report from the standardisation subcommittee of the International Continence Society. Urology. 2003; 61(1):37-49.

2. Andersson KE, Yoshida M. Antimuscarinics and the overactive detrusor - which is the main mechanism of action? Eur Urol. 2003;43(1): $1-5$.

3. Hegde SS. Muscarinic receptors in the bladder: from basic research to therapeutics. Br J Pharmacol. 2006;147 Suppl 2:S80-S87.

4. Abrams P, Andersson KE. Muscarinic receptor antagonists for overactive bladder. BJU Int. 2007;100(5):987-1006.

5. Irwin DE, Milsom I, Hunskaar S, et al. Population-based survey of urinary incontinence, overactive bladder, and other lower urinary tract symptoms in five countries: results of the EPIC study. Eur Urol. 2006;50(6):1306-1314.

6. Stewart WF, van Rooyen JB, Cundiff GW, et al. Prevalence and burden of overactive bladder in the United States. World J Urol. 2003; 20(6):327-336.

7. Dmochowski RR, Newman DK. Impact of overactive bladder on women in the United States: results of a national survey. Curr Med Res Opin. 2007;23(1):65-76

8. Coyne KS, Sexton CC, Irwin DE, Kopp ZS, Kelleher CJ, Milsom I. The impact of overactive bladder, incontinence and other lower urinary tract symptoms on quality of life, work productivity, sexuality and emotional well-being in men and women: results from the EPIC study. BJU Int. 2008;101(11):1388-1395.

9. Sexton CC, Coyne KS, Vats V, Kopp ZS, Irwin DE, Wagner TH. Impact of overactive bladder on work productivity in the United States: results from EpiLUTS. Am J Manag Care. 2009;15 Suppl 4:S98-S107.

10. Brown JS, McGhan WF, Chokroverty S. Comorbidities associated with overactive bladder. Am J Manag Care. 2000;6 Suppl 11:S574-S579.

11. Darkow T, Fontes CL, Williamson TE. Costs associated with the management of overactive bladder and related comorbidities. Pharmacotherapy. 2005;25(4):511-519.

12. Hu TW, Wagner TH, Bentkover JD, LeBlanc K, Zhou SZ, Hunt T. Costs of urinary incontinence and overactive bladder in the United States: a comparative study. Urology. 2004;63(3):461-465.

13. Hobbs F, Stoops N. Demographic Trends in the 20th Century. Washington (DC): United States Census Bureau, United States Government Printing Office; 2002. Available from: http://www.census. gov/prod/2002pubs/censr-4.pdf. Accessed 2010 Oct 15 .

14. Benner JS, Becker R, Fanning K, Jumadilova Z, Bavendam T, Brubaker L. Bother related to bladder control and health care seeking behavior in adults in the United States. $J$ Urol. 2009;181(6): 2591-2598. 
15. Morrison J, Birder L, Craggs M, et al. Neural control. In: Abrams P, Cardozo L, Khoury S, Wein A, editors. Incontinence. Jersey: Health Publications, Ltd.; 2005:363-422.

16. de Groat WC, Theobald RJ. Reflex activation of sympathetic pathways to vesical smooth muscle and parasympathetic ganglia by electrical stimulation of vesical afferents. J Physiol. 1976;259(1):223-237.

17. de Groat WC. Integrative control of the lower urinary tract: preclinical perspective. Br J Pharmacol. 2006;147 Suppl 2:S25-S40.

18. Ouslander JG. Management of overactive bladder. $N$ Engl J Med. 2004;350(8):786-799.

19. Andersson KE. Storage and voiding symptoms: pathophysiological aspects. Urology. 2003;62 Suppl 5B:3-10.

20. Andersson KE. Antimuscarinics for treatment of overactive bladder. Lancet Neurol. 2004;3(1):46-53.

21. Brading AF. A myogenic basis for the overactive bladder. Urology. 1997;50 Suppl 6A:57-67.

22. Levin RM, Longhurst PA, Monson FC, Kato K, Wein AJ. Effect of bladder outlet obstruction on the morphology, physiology, and pharmacology of the bladder. Prostate Suppl. 1990;3:9-26.

23. Gosling JA, Kung LS, Dixon JS, Horan P, Whitbeck C, Levin RM. Correlation between the structure and function of the rabbit urinary bladder following partial outlet obstruction. J Urol. 2000;163(4):1349-1356.

24. Mansfield KJ, Liu L, Mitchelson FJ, Moore KH, Millard RJ, Burcher E. Muscarinic receptor subtypes in human bladder detrusor and mucosa, studied by radioligand binding and quantitative competitive RT-PCR: changes in ageing. Br J Pharmacol. 2005;144(8):1089-1099.

25. Bschleipfer T, Schukowski K, Weidner W, et al. Expression and distribution of cholinergic receptors in the human urothelium. Life Sci. 2007;80(24-25):2303-2307.

26. Caulfield MP, Birdsall NJ. International Union of Pharmacology. XVII. Classification of muscarinic acetylcholine receptors. Pharmacol Rev. 1998;50(2):279-290.

27. Chess-Williams R. Muscarinic receptors of the urinary bladder: detrusor, urothelial and prejunctional. Auton Autacoid Pharmacol. 2002;22(3):133-145.

28. Finney SM, Andersson KE, Gillespie JI, Stewart LH. Antimuscarinic drugs in detrusor overactivity and the overactive bladder syndrome: motor or sensory actions? BJU Int. 2006;98(3):503-507.

29. Hawthorn MH, Chapple CR, Cock M, Chess-Williams R. Urothelium-derived inhibitory factor(s) influence detrusor muscle contractility in vitro. Br J Pharmacol. 2000;129(3):416-419.

30. Ditropan package insert (Marion Merrell Dow - US), 1992. PDR.

31. Douchamps J, Derenne F, Stockis A, Gangji D, Juvent M, Herchuelz A. The pharmacokinetics of oxybutynin in man. Eur J Clin Pharmacol. 1998;35(5):515-520.

32. Ditropan XL package insert (Ortho-McNeil Pharmaceutical, Inc.), 1999.

33. Macdiarmid SA. The evolution of transdermal/topical overactive bladder therapy and its benefits over oral therapy. Rev Urol. 2009;11(1):1-6.

34. Nitti VW, Sanders S, Staskin DR, et al. Transdermal delivery of drugs for urologic applications: basic principles and applications. Urology. 2006;67(4):657-664.

35. Zobrist RH, Schmid B, Feick A, Quan D, Sanders SW. Pharmacokinetics of the R- and S-enantiomers of oxybutynin and N-desethyloxybutynin following oral and transdermal administration of the racemate in healthy volunteers. Pharm Res. 2001;18(7):1029-1034.

36. Mukhtar H, Khan WA. Cutaneous cytochrome P-450. Drug Metab Rev. 1989;20(2-4):657-673.

37. Oxytrol [package insert]. Corona, California, Watson Pharma, Incorporated, 2003.

38. Davila GW, Daugherty CA, Sanders SW; Transdermal Oxybutynin Study Group. A short-term, multicenter, randomized double-blind dose titration study of the efficacy and anticholinergic side effects of transdermal compared to immediate release oral oxybutynin in treatment of patients with urge urinary incontinence. J Urol. 2001;166(1): $140-145$.

39. Gelnique ${ }^{\circledR}$ prescribing information.
40. Staskin DR, Robinson D. Oxybutynin chloride topical gel: a new formulation of an established antimuscarinic therapy for overactive bladder. Expert Opin Pharmacother. 2009;10(18):3103-3111.

41. Rovner ES, Wein AJ. Once-daily, extended-release formulations of antimuscarinic agents in the treatment of overactive bladder: a review. Eur Urol. 2002;41(1):6-14.

42. Olsson B, Szamosi J. Multiple-dose pharmacokinetics of a new oncedaily extended-release tolterodine formulation versus immediate release tolterodine. Clin Pharmacokinet. 2001;40(3):227-235.

43. Kim Y, Yoshimura N, Masuda H, de Miguel F, Chancellor MB. Intravesical instillation of human urine after oral administration of trospium, tolterodine and oxybutynin in a rat model of detrusor overactivity. BJU Int. 2006;97(2):400-403.

44. Staskin DR, Rosenberg MT, Sand PK, Zinner NR, Dmochowski RR. Trospium chloride once-daily extended release is effective and well tolerated for the treatment of overactive bladder syndrome: an integrated analysis of two randomised, phase III trials. Int J Clin Pract. 2009;63(12):1715-1723.

45. Haab F, Stewart L, Dwyer P. Darifenacin, an M3 selective receptor antagonist, is an effective and well-tolerated once-daily treatment for overactive bladder. Eur Urol. 2004;45(4):420-429.

46. Andersson KE. Potential benefits of muscarinic M3 receptor selectivity. Eur Urol Suppl. 2002;1:23-28.

47. Skerjanec A. The clinical pharmacokinetics of darifenacin. Clin Pharmacokinet. 2006;45(4):325-350.

48. Maniscalco M, Singh-Franco D, Wolowich WR, Torres-Colón R. Solifenacin succinate for the treatment of symptoms of overactive bladder. Clin Ther. 2006;28(9):1247-1272.

49. Brunton S, Kuritzky L. Recent developments in the management of overactive bladder: focus on the efficacy and tolerability of once daily solifenacin succinate $5 \mathrm{mg}$. Curr Med Res Opin. 2005;21(1): 71-80.

50. Ellsworth P. Fesoterodine for the treatment of urinary incontinence and overactive bladder. Ther Clin Risk Manag. 2009;5:869-876.

51. Nilvebrant L, Hallen B, Larsson G. Tolterodine - a new bladder selective muscarinic receptor antagonist: preclinical pharmacological and clinical data. Life Sci. 1997;60(13-14):1129-1136.

52. Michel MC. Fesoterodine: a novel muscarinic receptor antagonist for the treatment of overactive bladder syndrome. Expert Opin Pharmacother. 2008;9(10):1787-1796.

53. Nabi G, Cody JD, Ellis G, Herbison P, Hay-Smith J. Anticholinergic drugs versus placebo for overactive bladder syndrome in adults. Cochrane Database Syst Rev. 2006;4:CD003781.

54. Alhasso AA, McKinlay J, Patrick K, Stewart L. Anticholinergic drugs versus non-drug active therapies for overactive bladder syndrome in adults. Cochrane Database Syst Rev. 2006;4:CD003193.

55. Hay-Smith J, Herbison P, Ellis G, Morris A. Which anticholinergic drug for overactive bladder symptoms in adults. Cochrane Database Syst Rev. 2005;3:CD005429.

56. Chapple CR, Khullar V, Gabriel Z, Muston D, Bitoun CE, Weinstein D. The effects of antimuscarinic treatments in overactive bladder: an update of a systematic review and meta-analysis. Eur Urol. 2008;54(3):543-562.

57. Staskin DR, Dmochowski RR, Sand PK, et al. Efficacy and safety of oxybutynin chloride topical gel for overactive bladder: a randomized, double-blind, placebo controlled, multicenter study. J Urol. 2009; 181(4):1764-1772.

58. Abrams P, Andersson KE, Buccafusco JJ, et al. Muscarinic receptors: their distribution and function in body systems, and the implications for treating overactive bladder. Br J Pharmacol. 2006;148(5): $565-578$.

59. Scarpero HM, Dmochowski RR. Muscarinic receptors: what we know. Curr Urol Rep. 2003;4(6):421-428.

60. Ikeda K, Kobayashi S, Suzuki M, et al. M(3) receptor antagonism by the novel antimuscarinic agent solifenacin in the urinary bladder and salivary gland. Naunyn Schmiedebergs Arch Pharmacol. 2002;366(2): 97-103. 
61. Meek PD, Evang SD, Tadrous M, Roux-Lirange D, Triller DM, Gumustop B. Overactive bladder drugs and constipation: a meta-analysis of randomized, placebo-controlled trials. Dig Dis Sci. 2010 Jul 2. Epub ahead of print.

62. Dmochowski RR, Sand PK, Zinner NR, Gittelman MC, Davila GW, Sanders SW; Transdermal Oxybutynin Study Group. Comparative efficacy and safety of transdermal oxybutynin and oral tolterodine versus placebo in previously treated patients with urge and mixed urinary incontinence. Urology. 2003;62(2):237-242.

63. Dmochowski RR, Davila GW, Zinner NR, et al; Transdermal Oxybutynin Study Group. Efficacy and safety of transdermal oxybutynin in patients with urge and mixed urinary incontinence. J Urol. 2002;168(2):580-586.

64. Katz IR, Sands LP, Bilker W, DiFilippo S, Boyce A, D’Angelo K. Identification of medications that cause cognitive impairment in older people: the case of oxybutynin chloride. JAm Geriatr Soc. 1998;46(1): 8-13.

65. Lipton RB, Kolodner K, Wesnes K. Assessment of cognitive function of the elderly population: effects of darifenacin. J Urol. 2005;173(2): 493-498.

66. Noe L, Sneeringer R, Patel B, Williamson T. The implications of poor medication persistence with treatment for overactive bladder. Manag Care Interface. 2004;17(11):54-60.

67. Rosenblum N. Will the evolution of overactive bladder delivery systems increase patient compliance? Rev Urol. 2009;11(2):45-51.
68. Fong RL. Violence as a barrier to compliance for the hypertensive urban African American. J Natl Med Assoc. 1995;87(3):203-207.

69. Krueger KP, Felkey BG, Berger BA. Improving adherence and persistence: a review and assessment of interventions and description of steps toward a national adherence initiative. J Am Pharm Assoc. 2003;43(6):668-678.

70. Varadharajan S, Jumadilova Z, Girase P, Ollendorf DA. Economic impact of extended-release tolterodine versus immediate- and extended-release oxybutynin among commercially insured persons with overactive bladder. Am J Manag Care. 2005;11 Suppl 4:S140-S149.

71. Yu YF, Nichol MB, Yu AP, Ahn J. Persistence and adherence of medications for chronic overactive bladder/urinary incontinence in the California Medicaid program. Value Health. 2005;8(4):495-505.

72. Shaya FT, Blume S, Gu A, Zyczynski T, Jumadilova Z. Persistence with overactive bladder pharmacotherapy in a Medicaid population. Am J Manag Care. 2005;11 Suppl 4:S121-S129.

73. Sears CL, Lewis C, Noel K, Albright TS, Fischer JR. Overactive bladder medication adherence when medication is free to patients. $J$ Urol. 2010;183(3):1077-1081.

74. D’Souza AO, Smith MJ, Miller LA, Doyle J, Ariely R. Persistence, adherence, and switch rates among extended-release and immediaterelease overactive bladder medications in a regional managed care plan. J Manag Care Pharm. 2008;14(3):291-301.
Open Access Journal of Urology

\section{Publish your work in this journal}

The Open Access Journal of Urology is an international, peer-reviewed, open access journal publishing original research, reports, editorials, reviews and commentaries on all aspects of adult and pediatric urology in the clinic and laboratory including the following topics: Pathology, pathophysiology of urological disease; Investigation and treatment of

\section{Dovepress}

urological disease; Pharmacology of drugs used for the treatment of urological disease. The manuscript management system is completely online and includes a very quick and fair peer-review system, which is all easy to use. Visit http://www.dovepress.com/testimonials.php to read real quotes from published authors. 